\title{
PILOT STUDIES WITH A PHOTOGRAMMETRIC GLACIER LAKE OUTBURST FLOOD EARLY WARNING SYSTEM
}

\author{
Hans-Gerd Maas ${ }^{1}$, Christian Mulsow ${ }^{1}$, Anja Wendt ${ }^{2}$, Gino Casassa ${ }^{2}$ \\ ${ }^{1}$ Institute of Photogrammetry and Remote Sensing, Technische Universität Dresden, D-01062 Dresden, Germany \\ hans-gerd.maas@tu-dresden.de \\ ${ }^{2}$ Centro de Estudios Científicos (CECS), Valdivia, Chile
}

\section{Commission V, WG V/6}

KEYWORDS: Photogrammetric network, image sequence processing, disaster monitoring

\begin{abstract}
:
Glacier Lake Outburst Floods (GLOFs) depict an environmental risk with an increasing damage potential in many regions of the world. GLOFs are often caused by glacier margin lakes, which suddenly find a drainage path underneath the bottom of a glacier, which is destabilized and retreating as a consequence of local or global climate changes. In a typical GLOF event, a glacier margin lake may drain completely in 24 hours, causing a large flood wave in the area downstream the glacier.

The paper documents some recent GLOF events in the Northern Patagonian Icefield (Chile) and presents a terrestrial photogrammetric glacier margin lake monitoring system. The system is based on a camera taking images at regular time intervals. In these images, variations of the water level can be detected by tracking the water-land interface at pre-defined image spots. Due to the drainage mechanism, which is characterized by progressive erosion and melting at the bottom of the glacier, GLOFs are indicated by a progressive water level drop in the lake. Water level changes may be detected with subpixel accuracy by image sequence processing methods. If a 3D model of the lake bottom topography (or at least one height profile through the lake) exists, water level changes in monoscopic image sequences may be transformed into volume loss. The basic idea herein is the intersection of a terrain profile with a water level detected in the image and projected into object space. The camera orientation is determined through a GPS-supported photogrammetric network. Camera orientation changes, which may for instance be induced by wind, can be compensated by tracking some fiducial marks in the image.

The system has been used in a pilot study at two glacier margin lakes in the Northern Patagonian Icefield. These lakes have a depth of about 80 - 100 meters. The larger one has a length of $5 \mathrm{~km}$ and a maximum volume of about 200,000,000 cubic meters. During the pilot study, several GLOF events could be recorded and processed. Water level changes can be determined at decimeter level precision. The results prove the feasibility of the concept, which has to be completed by a data telemetry and alarm system.
\end{abstract}

\section{INTRODUCTION}

GLOFs occur in many regions of the world and are caused by various mechanisms. Regions with a high (or increasing) GLOF potential are for instance the Himalayas, Alaska, Iceland, the Andes and Patagonia. GLOFs often occur by the sudden drainage of lakes, which are dammed by glacier tongues or moraines.

With glaciers retreating in most regions of the world, the risk of GLOFs is increasing (Rosenzweig et al., 2007). This is partly caused by the increasing amount of melt water accumulating in glacier margin lakes. A major reason is in the fact that a retreating and thinning glacier tongue will give less detention to the hydrostatic pressure of the dammed lake water. This process is known as 'Glen mechanism' (Glen, 1954; Higgins, 1970): The increasing hydrostatic pressure of a glacier margin lake together with the decreasing detention from a thinning glacier enforces the development of a tunnel at the glacier bottom, through which the lake drains. During the process, this tunnel is widened by melting and erosion, causing a progressive lake drainage process. Some time after the complete drainage of the lake, the tunnel will collapse, triggered by glacier motion, and the lake will fill again, until it has reached a critical water level. This way, a GLOF cycle is initiated, which may last for weeks, months or years. 
The work described in this paper was performed in the Patagonian Icefield, the third largest continuous icefield in the world (after Antarctica and Greenland), where glaciers are also retreating (e.g. Rignot et al., 2003; Casassa et al., 2007) and where several strong GLOF events have occurred in the past few years.

An example of such a disastrous event is the GLOF at Lago Cachet II in the Northern Patagonian Icefield at 6.-7. April 2008 (Casassa et al., 2008). Lago Cachet II is dammed by the Glaciar Colonia (Figure 1).

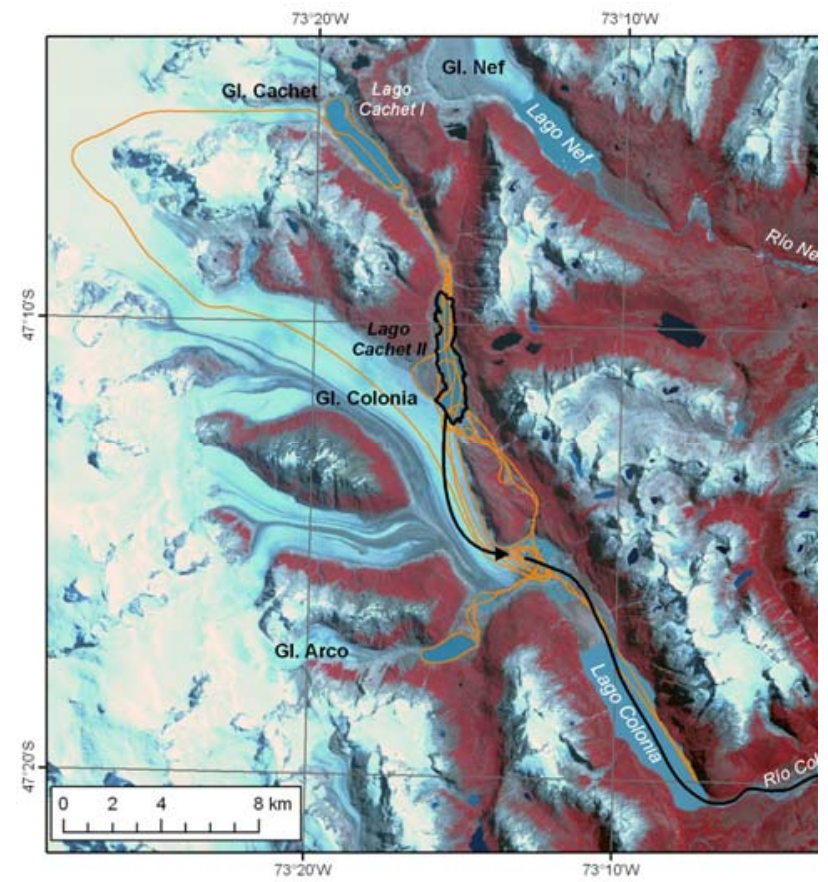

Figure 1: Satellite image of Lago Chachet II glacier lake drainage paths (in black) at Glaciar Colonia (Cassasa et al., 2009)

The lake has a length of $5 \mathrm{~km}$, a width of $1 \mathrm{~km}$, a maximum depth of $100 \mathrm{~m}$ and a volume of ca. 200.000.000 $\mathrm{m}^{3}$. For Glaciar Colonia, a surface decrease of $9.1 \mathrm{~km}^{2}$ (2.7\% of the total surface area) has been reported for 1979-2001 (Rivera et al., 2007); Masiokas et al. (2009) report a glacier front retreat by ca. $1 \mathrm{~km}$; Casassa (2009) reports a thinning of the glacier tongue, which is about $2 \mathrm{~m} / \mathrm{a}$ in the region of the Lago Cachet II contact.

In the evening of 8 . April 2008, the lake began to drain through a tunnel of $8 \mathrm{~km}$ length, which had developed at the glacier bottom. The waters flooded the Colonia River valley and flew further into the Rio Baker, the largest river in Chile, where the water level rose by $4.5 \mathrm{~m}$ within 48 hours and the discharge increased from $1200 \mathrm{~m}^{3} / \mathrm{s}$ to $3600 \mathrm{~m}^{3} / \mathrm{s}$ (report Dirección General de Aguas, 2008). Several similar events were observed in the time since then. Also for the close-by smaller Lago Nef Norte, which is dammed by Glaciar Nef, several GLOFs were reported since 2008.

In order to be able to warn (and possibly evacuate) the local residents, plans have been developed to establish an early warning system at critical lakes. Possible techniques are for instance pressure gauges or GPS buoys. Both, however, might be dam- aged by ice fall or by sudden changes in the geomorphology of the lake basin. As an alternative, the lakes might be observed by terrestrial cameras.

The goal of the work presented here was to perform a pilot study on the use of photogrammetric techniques for glacier margin lake water level change monitoring. This involves the choice and installation of a suitable camera system (section 2), techniques for monitoring water level changes in image sequences (section 3) and georeferencing techniques (section 4). Results from two pilot studies are shown in section 5.

\section{CAMERA SYSTEM}

In two field campaigns in 2009/2010, three cameras were placed at Glaciar Nef and Glaciar Colonia, taking images of Lago Nef Norte, Lago Cachet II a lake at the front of Glaciar Colonia in regular time intervals. Both field campaigns were 9day walking expeditions.

The cameras were Harbortronics time lapse cameras (Figure 2), consisting of an 11 Mpix off-the-shelf SLR camera, a timer, a waterproof body, a solar panel and a buffer battery.

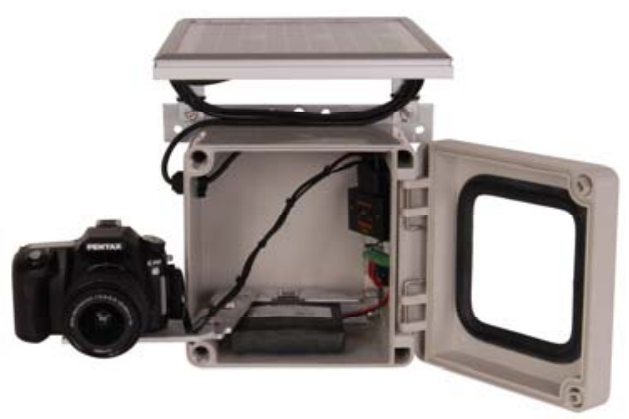

Figure 2: Harbortronics time lapse camera package

The cameras were installed on stable tripods (Figure 3). Some fiducials were installed in the foreground in order to verify the camera orientation stability and to correct for wind-induced orientation changes.

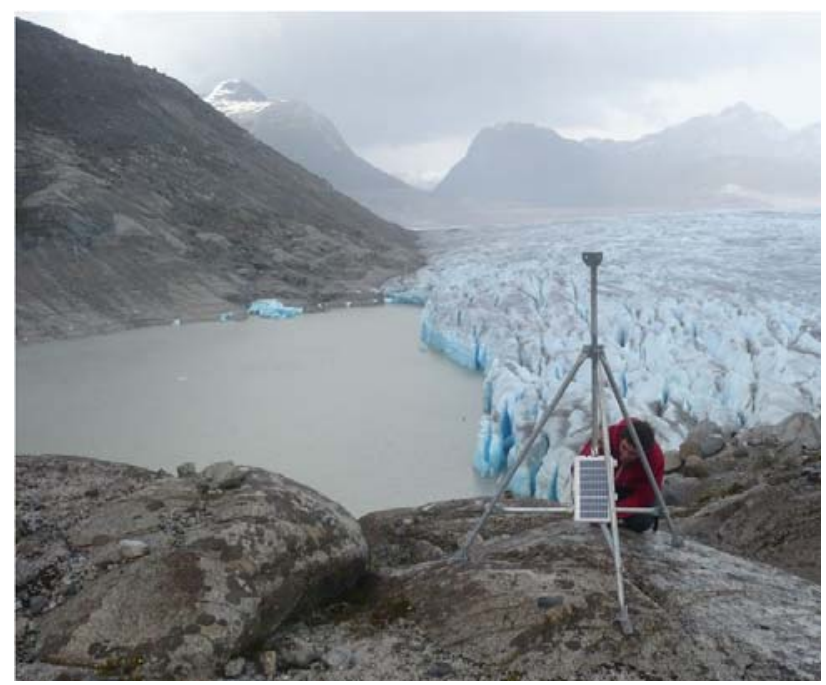

Figure 3: Harbortronics camera installation at Lago Nef Norte 


\section{IMAGE PROCESSING}

The image processing procedure can be divided into the following processing steps (Mulsow et al., 2011):

- Camera movement compensation: Camera movements (mainly rotations) may caused by various effects, for instance wind effects or human interference. In each image, the coordinates of the fiducials (at least two) were measured by least squares matching, taking the first image of a sequence as reference. From the fiducial coordinates, an image shift was computed and applied to correct for camera movement correction. Image rotations were not significant and thus neglected. In our sequences, image movements of a few pixels (with extremes of up to 42 pixels) could be observed.

- Water level measurement: So far, automatic procedures for water level measurement turned out to be not sufficiently reliable. Reasons were changing illumination conditions, sediment load in the water, reflections and ice on the water surface. Therefore, the water level was measured interactively in this pilot study. A future system will require a reliable technique for water level measurement in the images, which might also be based on NIR imagery.

- Object space transformation: The transformation from monoscopic image space water level measurements into object space coordinates (and thus water level heights) requires knowledge on the exterior and interior orientation of the camera as well as a local scale parameter. As only relative measurements (height changes) are to be determined, several neglect ions can be envisaged. The interior calibration parameters were determined by a pre-calibration of the cameras. The exterior orientation is described in section 4 . The local scale parameter is determined from the distance to the water level point at hand, the local surface gradient and the camera constant. For the determination of the distance and the local surface gradient, we need a digital terrain model of the lake basis or at least one height profile. Options for this are also discussed in section 4.

\section{GEOREFERENCING}

Figure 4 shows a camera image at Lago Cachet II.

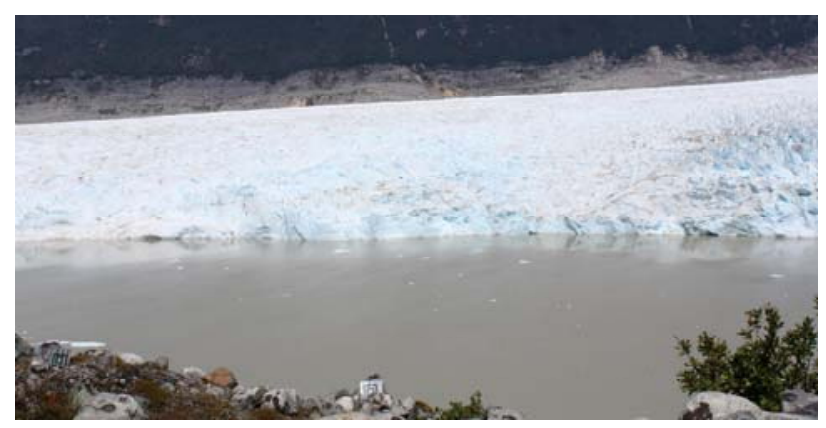

Figure 4: Camera image at Lago Cachet II

A multi-image GPS-supported photogrammetric network similar to the one shown by Maas et al. (2010) was established for the determination of the camera orientation parameters. The network was hampered by some local conditions, especially the inaccessibility of large parts of the glacier surface and the regions behind the glacier.

The following information was introduced into the network:

- Image tie point measurements: At each camera station, a network of 5-7 images was taken. The base lengths between these images were limited to $100-200 \mathrm{~m}$ by local constraints. In these images, tie points were measured interactively. An automatic measurement, for instance in bundler, failed doe to the difficult image contrast situation.

- GPS measurements: The coordinates of the camera stations of the network were measured by GPS. Due to load restrictions on a 9-day walking expedition, only Garmin handheld GPS receivers were available.

- Water level constraints: The knowledge on a horizontal water level was introduced as a constraint into the bundle adjustment, yielding a number of coplanar points.

- Control points: Due to the inaccessibility of the terrain, only very few control points could be determined.

Obviously, these conditions do not allow for a very high precision in the network adjustment and the camera orientation parameter determination. The achievable precision can, however, be considered sufficient due to the fact that only relative height measurements are to be determined. For instance, an error of 20 $\mathrm{m}$ at a point $1000 \mathrm{~m}$ from the camera leads to a local scale error of $2 \%$, which translates into a $10 \mathrm{~cm}$ height change error when the water level drops by $5 \mathrm{~m}$. In future projects, aerial images or high resolution satellite images might also be used to support the camera orientation process.

As discussed in section 3, the image space to object space transformation procedure requires the knowledge to the local terrain gradient in vertical image coordinate direction. Several options exist to provide this information:

- Airborne laserscanning: For one of the lakes, an airborne laserscanner dataset exists, which was by change taken at a time when the lake was partly drained.

- Photogrammetric DTM generation: By chance, Lago Nef Norte completely drained during our 2010 field campaign. From that event, a number of amateur camera photos of the empty lake basin exist. So far, attempts to automatically generate a lake basin DTM from these images, for instance by Bundler, failed due to the suboptimal image contrast situation.

- Photogrammetric height profile generation: Two of the photogrammetric network images for the georeferencing procedure as described above were used for the interactive measurement of a height profile of the visible part of the lake basin (see principle in figure 5).

- Image sequence analysis: In our future work, the image sequences with the changing water level themselves will be used to determine the lake basin DTM, treating the water level lines (with known height) as contour lines after a rectification to the horizontal lake surface. 


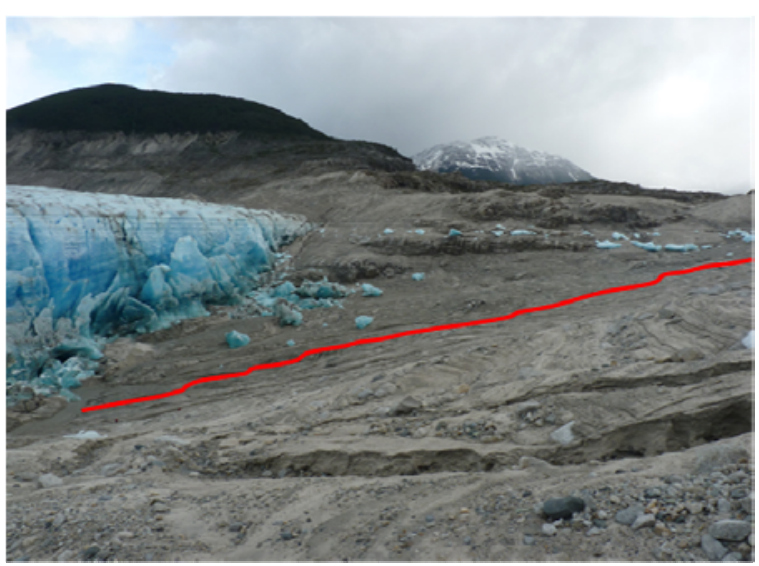

Figure 5: Lake basin profile for slope determination

\section{RESULTS}

In the course of the pilot study, one image sequence at Lago Nef Norte and one at Lago Cachet II were acquired and processed. The results are shown in Figure 6 and Figure 7.

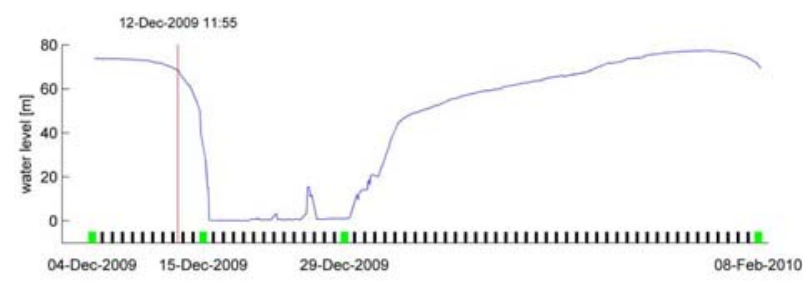

Figure 6: Water level at Lago Nef Norte over a two months period

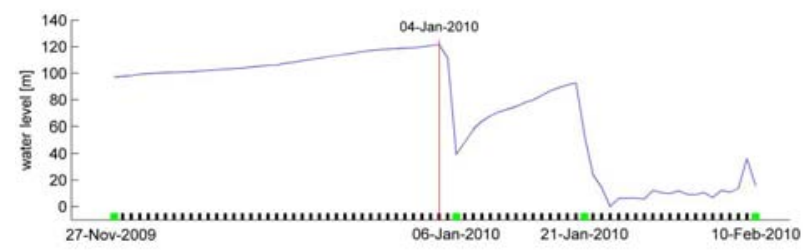

Figure 7: Water level at Lago Cachet II over a two months period

At Lago Nef Norte, seven images per day were taken in two hour intervals between 4.12.2009 and 8.2.2010. At Lago Chachet II, a sequence from 27.11.2009 to 10.2.2010 with only one image per day was available. The sequence at Lago Chachet II shows two GLOF events within two weeks (but both not with a complete drainage of the lake), the sequence at Lago Nef Norte shows one (complete) GLOF. In fact, Lago Nef Norte drained again at 10.2.2010, just after the end of the sequence.

As mentioned above, both the interactive image space water level measurement and the sub-optimal photogrammetric network conditions did not allow for a very high precision. However, while the absolute height precision is in the meter-range, the relative precision (which is relevant for GLOF prediction) can be estimated at a few decimeters.

\section{CONCLUSION}

In the pilot studies, the feasibility of a photogrammetric GLOF monitoring system could be shown. Cameras were set up at two glaciers in the Patagonian Icefield, and two image sequences containing three GLOF events were processed.

Future work will mainly address the aspect of reliable automatic water level measurement from image sequences as well as a contour-based lake basin DTM generation procedure. Several local constraints in photogrammetric network deteriorate the height accuracy. However, a relative precision of a few decimetres could be achieved. Considering typical GLOF mechanisms, this is sufficient for an early warning system. Exploiting the improvement potential in the georeferencing procedure, a relative water level height determination precision of about one decimetre (or even better) can be predicted.

Obviously, the photogrammetric system is only one part of an early warning system. The system has to be completed by a data telemetry system as well as warning and evacuation schemes. A visual camera based system will not be able to take images at night. However, GLOFs occur usually in summer in regions of larger latitudes, so that one must mostly only anticipate short interruptions of the image sequences of a few hours; this can be tolerated due to the progressive development of typical GLOFs, which can also be seen in Figure 6 and Figure 7.

\section{Acknowledgement:}

The pilot studies were conducted in close cooperation between CECS (Valdivia, Chile) and TU Dresden (Germany). The work was supported by Fondo Nacional de Desarrollo Científico y Tecnológico (FONDECYT) and the BMBF International Bureau. We would also like to express our thanks to Jonathan Leidich and Felipe Henríquez from Patagonia Adventure Expeditions for their support and the excellent organization of the 9day expedition to the Northern Patagonian Icefield.

\section{References}

Casassa, G., Rivera, A., Haeberli, W., Jones, G., Kaser, G., Ribstein, P., Schneider, C., 2007: Current status of Andean glaciers. Global and Planetary Change, Vol. 59, pp. 1-9

Casassa, G., Leidich, J., Rivera, A., Wendt, J., Ordenes, F. ,Escobar, F. ,Guzmán, F., Carrasco, J., López, P., 2008: Sudden Drainage of Glacial Lake Cachet 2, Patagonia. Fourth EGU Alexander von Humboldt International Conference 'The Andes: Challenge for Geosciences’. FCFM Universidad de Chile, Santiago, Chile, Nov. 24-28, 2008

Casassa, G., 2009: Recent drainage events of glacial Lake Cachet 2, Patagonia. Presentation at the General Assembly of the European Geosciences Union, Vienna

Glen, W., 1954: The stability of ice-dammed lakes and other water-filled holes in glaciers. Journal of Glaciology, Vol. 2, No. 15 , pp. 316-18 
Higgins, A., 1970: On some ice-dammed lakes in the Frederikshåb district, south-west Greenland. Meddelelser Fra Dansk Geologisk Forening 19, pp. 378-97

Maas, H.-G., Schneider, D., Schwalbe, E., Casassa, G., Wendt, A. (2010): Photogrammetric techniques for the determination of spatio-temporal velocity fields at Glaciar San Rafael in the Northern Patagonian Icefield. International Archives of Photogrammetry, Remote Sensing and Spatial Information Sciences, Vol. 38, Part 5.

Masiokas, M., Rivera, A., Espizua, L., Villalba, R., Delgada, S., Aravena, J., 2009: Glacier fluctuations in extratropical South America during the past 1000 years. Palaeogeography, Palaeoclimatology, Palaeoecology, Vol. 281, pp. 242-268

Mulsow, C., Maas, H.-G., Wendt, A., Casassa, G. (2011): Photogrammetrische Überwachung von Gletscherrandseen. Beiträge zur DGPF-Jahrestagung, DGPF Tagungsband 20/2011

Rignot, E., Rivera, A., Casassa, G., 2003: Contribution of the Patagonia icefields of South America to global sea level rise. Science, Vol. 302, pp. 434-437

Rivera, A., Benham, T., Casassa, G., Bamber, J., Dowdeswell, J., 2007: Ice elevation and areal changes of glaciers from the Northern Patagonia Icefield, Chile. Global and Planetary Change Vol. 59, pp. 126-137

Rosenzweig, C., Casassa, G., Karoly, D., Imeson, A., Liu, C., Menzel, A., Rawlins, S., Root, T., Seguin, B., Tryjanowski, P., 2007: Assessment of observed changes and responses in natural and managed systems. Climate Change 2007: Impacts, Adaptation and Vulnerability. Contribution of Working Group II to the Fourth Assessment Report of the Intergovernmental Panel on Climate Change (Eds. M. Parry et al.), Cambridge University Press, pp. 79-131 